\title{
Is FEV1 associated with quality of life in children with cystic fibrosis? An original article
}

\author{
Rohola Shirzadi $^{\circledR}$, Safoura Navaei ${ }^{\circledR}$, Mohammadreza Modaresi $^{(\mathbb{}}$, Farzad Masiha $^{2 *(}$ \\ 'Pediatric Respiratory and Sleep Medicine Research Center, Children's Medical Center, Tehran University of Medical Sciences, Tehran, Iran \\ ${ }^{2}$ Pediatric Infectious Diseases Research Center, Mazandaran University of Medical Sciences, Sari, Iran
}

\section{*Correspondence to Farzad Masiha, \\ Email: dr.masiha_56@yahoo. com,fmasiha@mazums.ac.ir \\ Received 26 Sep. 2019 Accepted 9 Dec. 2019 \\ Published online 24 Dec. 2019}

Keywords: Pulmonary function, Cystic fibrosis, Spirometry, Quality of life

\begin{abstract}
Introduction: Cystic fibrosis (CF) is a serious genetic life-shortening disease. Quality of life (QoL) measurement related to CF children is a relatively new field of research, which includes the patient's perspective in research and clinical practice.

Objectives: This study aimed to evaluate the QoL in children with CF and its association with FEV1 (forced expiratory volume in 1 second).

Patients and Methods: This cross-sectional study was carried out on 7-14 years old children with CF attending children's medical center from March 2017 to March 2018. Throat swab cultures and spirometry evaluation was performed for all patients. FEV1 was determined and the 6-min walk test (6MWT) was conducted. The patient's psychological status was assessed using the Persian version of pediatric QoL inventory. ANOVA, test, and chisquare tests were used for data analysis.

Results: Seventy-six subjects with the mean age of $10.49 \pm 3.18$ years were studied since $59 \%$ of them ( $n=44)$ were boys. The mean total QoL was 65.34 \pm 17.73 . Patients with lower pulmonary function had a lower QoL. There was a significant association between FEV1 and school and emotional functioning $(P=0.005$ and $P=0.002$, respectively). A significant association was found between SPO2 (peripheral capillary oxygen saturation) reduction after $6 \mathrm{MWT}$ and FEV1 decline $(P=0.001)$. Additionally, a significant association was detected between FEV1 and the distance walked during 6MWT $(P=0.030)$.

Conclusion: Regarding the association between pulmonary function and QoL in CF patients and lower QoL score in our study, the importance of assessing pulmonary function in these patients should not be neglected.
\end{abstract}

\section{Introduction}

Cystic fibrosis (CF) is a serious genetic life-shortening disease transmitted in the autosomal recessive mode with an incidence rate of 1 in 4500 births in Europe and the USA (1). It is a chronic and progressive disease with diverse clinical manifestations occurring very early in childhood, sometimes from birth (2). It is dominated by exocrine pancreatic insufficiency and chronic lung infection in its classical form. The prognosis and mortality of CF are tightly affected by respiratory disease (3) while its mortality rate varies from $1.8 \%$ per year in America to 30-50\% in developing countries (2).

Mutations in the gene encoding the CFTR (CF transmembrane conductance regulator) causes it and pulmonary insufficiency is the main cause of death in these patients (4). Several methods are used to assess pulmonary disease severity in CF patients including spirometry, chest imaging and quality of life (QoL) questionnaires. The best method for assessing CF lung disease is forced expiratory

\begin{abstract}
Key point
Regular assessment of pulmonary function by the sixminute walk test can improve the quality of life in cystic fibrosis children.
\end{abstract}

volume in 1 second $\left(\mathrm{FEV}_{1}\right)$ compared to a reference population ( $\mathrm{FEV}_{1} \%$ predicted) (5). Functional capacity is an important diagnostic tool and is a simple and reliable test for periodic patient surveys because it reflects the cardiorespiratory status, QoL and prognosis. The six-minute walk test (6MWT) is another inexpensive, easy and repeatable test for assessing the functional capacity of children and adolescents with CF (6).

Lung function is an important indicator of cystic fibrosis disease status while those with better FEV1 predicted have a better QoL (7). The progressive nature of CF disease and the demanding treatment burden have the potential to interfere with daily living of these patients and affect their health-related

\footnotetext{
Copyright (C) 2020 The Author(s); Published by Nickan Research Institute. This is an open-access article distributed under the terms of the Creative Commons Attribution License (http://creativecommons.org/licenses/by/4.0), which permits unrestricted use, distribution, and reproduction in any medium, provided the original work is properly cited.
} 
QoL (8). QoL measurement related to CF children, as an independent predictor of survival, is a relatively new field of research, which includes the patient's perspective in research and clinical practice (9). Considerable significance data is achieved from such studies that help understanding children's psychosocial functioning and development like their perception of illness and its effect on their daily life (10).

\section{Objectives}

This study aimed to evaluate the QoL in children with CF and to examine its association with FEV1.

\section{Patients and Methods}

\section{Participants and procedure}

In this cross-sectional study, children with CF attending children's medical center as a primary care hospital in Tehran, Iran from March 2017 to March 2018 participated. Subjects included children 7-14 years diagnosed as CF based on compatible clinical features with sweat chloride values of $\geq 60 \mathrm{mmol} / \mathrm{L}$ on two occasions or with two known identified CF-causing CFTR mutations and a sweat chloride value of $\geq 60 \mathrm{mmol} / \mathrm{L}$. In case of sweat chloride values of $<60 \mathrm{mmol} / \mathrm{L}$, at least two of the following must exist; two CF mutations, abnormal mucosal potential, and typical clinical manifestations of CF (11). In case of acute respiratory infection, clinical exacerbation, mental retardation, chronic diseases, and reading difficulties, patients were excluded.

All patients with CF who met the inclusion criteria were asked to participate and were examined by an expert pediatric pulmonologist at the hospital clinic. Then, weight and height of the patient were measured and body mass index (BMI) was calculated. Additionally, throat swab cultures and spirometry evaluation were performed for all patients. Finally, FEV1 was determined. FEV1 was presented as the percentage of the predicted value based on gender, age and height. Then, the 6MWT was performed.

\section{Evaluation of health-related QoL}

The individuals' psychological status was assessed using the Persian version of pediatric QoL inventory (PedsQL ${ }^{\mathrm{TM}}$ 4.0 generic core scale). It is a child self-report (8-12 years), adolescent self-report (9-16 years) and parent proxy-report scale established to assess health-related QoL in children and adolescents by 23 questionnaires consisting of 4 domains of functioning to evaluate physical functioning, social functioning, emotional responses, and school functioning (12). The questions had to be answered keeping in mind the physical and psychological health status over the two weeks preceding the day of administration of the questionnaire (13). A 5-point response scale ranges from 0 (never a problem) to 4 (almost always a problem). Each item is reverse-scored and linearly transformed to a 0-100 scale, with higher agreement placed at the top of the scale $(14,15)$. Content validity of PedsQL was 0.84 and of the four subscales, physical, emotional, social, and school functioning were $0.80,0.86,0.83$, and 0.88 , respectively. Construct validity was good and it had a good internal consistency ( $\alpha=0.82$ ) (15). Our participants aged between 7 to 14 years old and if a child was unable to complete the self-report form, the study administrator read a questionnaire aloud for him/her and avoided suggesting a specific answer by avoiding intonation change. Parents selfadministered the questionnaire after a brief instruction from the administrator (14).

\section{Ethics statements}

This study was approved by the ethics committee of Tehran University of Medical Sciences. The study was conducted according to the 1964 Helsinki Declaration and its later amendments. The parents of all subjects provided written and informed consent. This paper is the result of pediatric pulmonology fellowship thesis of Farzad Masiha at this university.

\section{Statistical analysis}

Descriptive statistics (mean $\pm \mathrm{SD}$ ) were used for all continuous variables, and frequencies were generated for the non-continuous variables. To compare means, $t$ test and ANOVA test were applied and chi-square test was used to compare ratios. Statistical analysis was performed using SPSS software version 18.0 and a $P$ value less than 0.05 was considered being statistically significant.

\section{Results}

The study population included 76 subjects diagnosed with CF with the mean age of $10.49 \pm 3.18$ years, and mean BMI of $16.21 \pm 2.83 \mathrm{~kg} / \mathrm{m}^{2}$. About $59 \%$ of them $(\mathrm{n}=44)$ were boys. The mean age of the patients at the time of CF diagnosis was $19.46 \pm 29.04$ months (range 1 month to 9 years). Thirty patients (17\%) were diagnosed during the study and the remaining patients had already been diagnosed. Fifty-six percent of the parents had no familial relationship and the first symptom at the beginning of the diagnosis was gastrointestinal symptoms in $44.8 \%$ (34 cases), and pulmonary symptoms in $55.3 \%$ (42 cases). The association between QoL components and pulmonary function in CF patients is shown in Table 1.

Spirometry results showed that mean FEV1\% predicted was $75.9 \pm 21.72 \%$ and mean $\mathrm{FVC} \%$ (forced volume vital capacity) predicted was $72.43 \pm 17.60 \%$. The FEV1 predicted estimates were significantly associated with emotion and school functioning domains $(P=0.002$ and $P=0.005$, respectively).

Around 28.9\% (22 cases) of the patients had positive Pseudomonas spp. throat swab sample culture while $22.4 \%$ (17 cases) had Staphylococcus and 15.8\% (12 cases) were positive for mucoid Pseudomonas in their throat swab culture. About $82 \%$ of patients had insufficient elastase (pancreatic exocrine insufficiency). No significant association was found between BMI and FEV1, but patients 
Table 1. The association between quality of life (QoL) components and pulmonary function in CF patients

\begin{tabular}{lc}
\hline & Mean \pm SD \\
\hline Sweat chloride $(\mathrm{mmol} / \mathrm{L})$ & $89.72 \pm 18.52$ \\
FEV1 $\%$ ) & $75.90 \pm 21.72$ \\
Heart Rate before 6MWT $(\mathrm{n} / \mathrm{min})$ & $92.69 \pm 13.33$ \\
\hline Heart Rate after 6MWT $(\mathrm{n} / \mathrm{min})$ & $118.32 \pm 19.10$ \\
SPO2 before 6MWT & $93.59 \pm 2.22$ \\
SPO2 after 6MWT $(\%)$ & $88.94 \pm 4.38$ \\
Distance walked in 6MWT $(\mathrm{m})$ & $447.39 \pm 84.09$ \\
Physical & $61.68 \pm 24.13$ \\
Emotion & $66.57 \pm 22.32$ \\
Social & $70.21 \pm 21.05$ \\
School & $65.08 \pm 20.53$ \\
Total QoL & $65.34 \pm 17.73$ \\
\hline
\end{tabular}

with higher BMI had better FEV1 so that the mean FEV1 in patients with BMI higher than $20 \mathrm{~kg} / \mathrm{m}^{2}$ was $80.1 \%$ and in BMI lower than $20 \mathrm{~kg} / \mathrm{m}^{2}$, it was $74.3 \%(P=0.159)$.

The mean total QoL was $65.34 \pm 17.73$. Table 2 shows the QoL domain scores for the children with CF based on FEV1 categories. School attendance of the children was found to be an important factor affecting several fields of the QoL including physical $(P=0.001)$, emotional $(P=0.014)$, social $(P=0.001)$, and total QoL score $(P=0.001)$.

No statistically significant correlation was found between QoL scores and age at diagnosis $(P=0.231)$.
Patients with lower pulmonary function had a lower QoL. There was a significant association between FEV1 and school and emotional functioning $(P=0.005$ and $P=0.002$, respectively) but there was no significant association with other components of the QoL questionnaire including physical and social functioning and total QoL score ( $P=0.462, P=0.506$ and $P=0.063$, respectively).

A significant association was found between SPO2 (peripheral capillary oxygen saturation) reduction after 6MWT and FEV1 decline $(P=0.001)$. Additionally, a significant association was found between the distance walked during 6MWT and FEV1 $(P=0.030)$. There was a significant association between SPO2 before and after the $6 \mathrm{MWT}$ test and the distance walked over a span of 6 minutes ( $P=0.007$ and $P=0.001$, respectively) (Tables 3, 4 and Figure 1).

\section{Discussion}

$\mathrm{CF}$ is a relatively common disease causing lung failure, decreasing life-expectancy and QoL (16). The prevalence of $\mathrm{CF}$ is increasing worldwide. In countries with higher prevalence of $\mathrm{CF}$, early detection of the disease and screening of newborns is of particular importance (2). In these patients, lung disease starts in first months of life and remains the predominant cause of morbidity and mortality (17).

In this study, the mean total QoL score was 65.34 17.73 . Researches on the QoL of CF patients has led to different

Table 2. Quality of life (QoL) domain scores for the children with CF based on FEV1 categories

\begin{tabular}{|c|c|c|c|c|c|c|c|}
\hline & & \multicolumn{5}{|c|}{ FEV1 } & \multirow{2}{*}{ Total } \\
\hline & & $<30 \%$ & $30-49 \%$ & $50-69 \%$ & $70-89 \%$ & $>90 \%$ & \\
\hline \multirow{5}{*}{ Physical function } & $<25$ & $0(0.0 \%)$ & $0(0.0 \%)$ & $0(0.0 \%)$ & $1(100.0 \%)$ & $0(0.0 \%)$ & $1(100.0 \%)$ \\
\hline & $25-50$ & $1(4.0 \%)$ & $3(12.0 \%)$ & $5(20.0 \%)$ & $9(36.0 \%)$ & $7(28.0 \%)$ & $25(100.0 \%)$ \\
\hline & $50-75$ & $1(3.6 \%)$ & $2(7.1 \%)$ & $7(25.0 \%)$ & $14(50.0 \%)$ & $4(14.3 \%)$ & $28(100.0 \%)$ \\
\hline & $>50$ & $0(0.0 \%)$ & $1(4.5 \%)$ & $6(27.3 \%)$ & $7(31.8 \%)$ & $8(36.4 \%)$ & $22(100.0 \%)$ \\
\hline & Total & $2(2.6 \%)$ & $6(7.9 \%)$ & $18(23.7 \%)$ & $31(40.8 \%)$ & $19(25.0 \%)$ & $76(100.0 \%)$ \\
\hline \multirow{5}{*}{$\begin{array}{l}\text { Emotional } \\
\text { function }\end{array}$} & $<25$ & $2(33.3 \%)$ & $1(16.7 \%)$ & $1(16.7 \%)$ & $1(16.7 \%)$ & $1(16.7 \%)$ & $6(100.0 \%)$ \\
\hline & $25-50$ & $0(0.0 \%)$ & $3(23.1 \%)$ & $4(30.8 \%)$ & $4(30.8 \%)$ & $2(15.4 \%)$ & $13(100.0 \%)$ \\
\hline & $50-75$ & $0(0.0 \%)$ & $1(4.8 \%)$ & $6(28.6 \%)$ & $8(38.1 \%)$ & $6(28.6 \%)$ & $21(100.0 \%)$ \\
\hline & $>50$ & $0(0.0 \%)$ & $1(2.8 \%)$ & $7(19.4 \%)$ & $18(50.0 \%)$ & $10(27.8 \%)$ & $36(100.0 \%)$ \\
\hline & Total & $2(2.6 \%)$ & $6(7.9 \%)$ & $18(23.7 \%)$ & $31(40.8 \%)$ & $19(25.0 \%)$ & $76(100.0 \%)$ \\
\hline \multirow{5}{*}{$\begin{array}{l}\text { Social } \\
\text { function }\end{array}$} & $<25$ & $0(0.0 \%)$ & $1(100.0 \%)$ & $0(0.0 \%)$ & $0(0.0 \%)$ & $0(0.0 \%)$ & $1(100.0 \%)$ \\
\hline & $25-50$ & $0(0.0 \%)$ & $1(11.1 \%)$ & $2(22.2 \%)$ & $4(44.4 \%)$ & $2(22.2 \%)$ & $9(100.0 \%)$ \\
\hline & $50-75$ & $2(5.7 \%)$ & $25.7 \%()$ & $9(25.7 \%)$ & $15(42.9 \%)$ & $7(20.0 \%)$ & $35(100.0 \%)$ \\
\hline & $>50$ & $0(0.0 \%)$ & $2(6.5 \%)$ & $7(22.6 \%)$ & $12(38.7 \%)$ & $10(32.3 \%)$ & $31(100.0 \%)$ \\
\hline & Total & $2(2.6 \%)$ & $6(7.9 \%)$ & $18(23.7 \%)$ & $31(40.8 \%)$ & $19(25.0 \%)$ & $76(100.0 \%)$ \\
\hline \multirow{5}{*}{$\begin{array}{l}\text { School } \\
\text { function }\end{array}$} & $<25$ & $2(66.7 \%)$ & $0(0.0 \%)$ & $0(0.0 \%)$ & $1(33.3 \%)$ & $0(0.0 \%)$ & $3(100.0 \%)$ \\
\hline & $25-50$ & $0(0.0 \%)$ & $2(15.4 \%)$ & $2(15.4 \%)$ & $6(46.2 \%)$ & $3(23.1 \%)$ & $13(100.0 \%)$ \\
\hline & $50-75$ & $0(0.0 \%)$ & $3(9.7 \%)$ & $8(25.8 \%)$ & $14(45.2 \%)$ & $6(19.4 \%)$ & $31(100.0 \%)$ \\
\hline & $>50$ & $0(0.0 \%)$ & $0(0.0 \%)$ & $6(25.0 \%)$ & $9(37.5 \%)$ & $9(37.5 \%)$ & $24(100.0 \%)$ \\
\hline & Total & $2(2.8 \%)$ & $5(7.0 \%)$ & $16(22.5 \%)$ & $30(42.3 \%)$ & $18(25.4 \%)$ & $71(100.0 \%)$ \\
\hline \multirow{4}{*}{ QoL } & $25-50$ & $2(18.2 \%)$ & $2(18.2 \%)$ & $2(18.2 \%)$ & $4(36.4 \%)$ & $1(9.1 \%)$ & $11(100.0 \%)$ \\
\hline & $50-75$ & $0(0.0 \%)$ & $3(7.0 \%)$ & $9(20.9 \%)$ & $21(48.8 \%)$ & $10(23.3 \%)$ & $43(100.0 \%)$ \\
\hline & $>75$ & $0(0.0 \%)$ & $1(4.5 \%)$ & $7(31.8 \%)$ & $6(27.3 \%)$ & $8(36.4 \%)$ & $22(100.0 \%)$ \\
\hline & Total & $2(2.6 \%)$ & $6(7.9 \%)$ & $18(23.7 \%)$ & $31(40.8 \%)$ & $19(25.0 \%)$ & $76(100.0 \%)$ \\
\hline
\end{tabular}


Table 3. The mean SPO2 after 6MWT and FEV1 in CF patients

\begin{tabular}{lccccc}
\hline \multirow{2}{*}{ FEV1 } & \multicolumn{4}{c}{ SPO2 } & \multirow{2}{*}{ Total } \\
\cline { 2 - 5 } & $<\mathbf{8 5 \%}$ & $\mathbf{8 5 - 9 0} \%$ & $\mathbf{9 0 - 9 5 \%}$ & $\mathbf{> 9 5} \%$ & \\
\hline$<30 \%$ & $2(2.6 \%)$ & $0(0.0 \%)$ & $0(0.0 \%)$ & $0(0.0 \%)$ & $2(2.6 \%)$ \\
$30-49 \%$ & $2(2.6 \%)$ & $3(3.9 \%)$ & $0(0.0 \%)$ & $1(1.3 \%)$ & $6(7.9 \%)$ \\
$50-69 \%$ & $2(2.6 \%)$ & $11(14.5 \%)$ & $5(6.6 \%)$ & $0(0.0 \%)$ & $18(23.7 \%)$ \\
$70-89 \%$ & $1(1.3 \%)$ & $13(17.1 \%)$ & $17(22.4 \%)$ & $0(0.0 \%)$ & $31(40.8 \%)$ \\
$>90 \%$ & $0(0.0 \%)$ & $7(9.2 \%)$ & $9(11.8 \%)$ & $3(3.9 \%)$ & $19(25.0 \%)$ \\
Total & $7(9.2 \%)$ & $34(44.7 \%)$ & $31(40.8 \%)$ & $4(5.3 \%)$ & $76(100.0 \%)$ \\
\hline
\end{tabular}

Table 4. Association between SPO2 before the 6MWT test and FEV1

\begin{tabular}{lcccc}
\hline \multirow{2}{*}{ FEV1 } & \multicolumn{3}{c}{ The walked distance } & \multirow{2}{*}{ Total } \\
\cline { 2 - 4 } & $\mathbf{< 4 0 0}$ & $\mathbf{4 0 0 - 5 0 0}$ & $\mathbf{> 5 0 0}$ & \\
\hline$<30 \%$ & $2(2.6 \%)$ & $0(0.0 \%)$ & $0(0.0 \%)$ & $2(2.6 \%)$ \\
$30-49 \%$ & $3(3.9 \%)$ & $2(2.6 \%)$ & $1(1.3 \%)$ & $6(7.9 \%)$ \\
$50-69 \%$ & $2(2.6 \%)$ & $11(14.5 \%)$ & $5(6.6 \%)$ & $18(23.7 \%)$ \\
$70-89 \%$ & $7(9.2 \%)$ & $12(15.8 \%)$ & $12(15.8 \%)$ & $31(40.8 \%)$ \\
$>90 \%$ & $1(1.3 \%)$ & $9(11.8 \%)$ & $9(11.8 \%)$ & $19(25.0 \%)$ \\
Total & $15(19.7 \%)$ & $34(44.7 \%)$ & $27(35.5 \%)$ & $76(100.0 \%)$ \\
\hline
\end{tabular}

results. The total QoL score in studies by Driscoll et al was $86.22 \pm 11.27$ (18), in the study of Vandekerckhove et al was $81.9 \pm 9.9(12)$, in the study of Cohen et al (19), it was $72.8 \pm 26.1$ and in the study by van Horck et al (20), it was $68.6 \pm 11.1$, which were higher than our results. Due to early diagnosis, medical treatment and awareness of patients and their parents, patients in these studies had a better QoL. Additionally, the cultural differences between countries, different CF care and health insurance systems could be other reasons. Some questions like social functioning in the QoL questionnaire are interpreted differently.

The predicted FEV1 estimates were significantly associated with emotion and school functioning domains. Borawska-Kowalczyk et al identified a significant correlation between QoL and disease severity (21). No correlation was found between the change in Healthrelated QoL (HRQoL) and FEV1 change in the study by van Horck et al (20). Accordingly, in the study by Abbott et al, the $\mathrm{FEV} \%$ predicted variance-covariance estimates were significant for all domains except body image. The difference in results may be due to the age group of the patients. However, Abbott et al evaluated QoL in children aged above 16 years but we studied 7-14 year-old children (7).

In our study, patients with lower pulmonary function had a lower QoL. In addition, patients with a higher FEV1 had a significantly better 6MWT result. In addition, a significant association was found between distance walked in 6MWT and the resting heart rate. In the study of Stollar and colleagues, patients with FEV1 $>70 \%$ had better 6 MWT results and had a meaningful relationship (22). Likewise, in the study by Ketchell et al, the association between distance in 6MWT and the resting heart rate was significant (23). Martin and colleagues found a significant

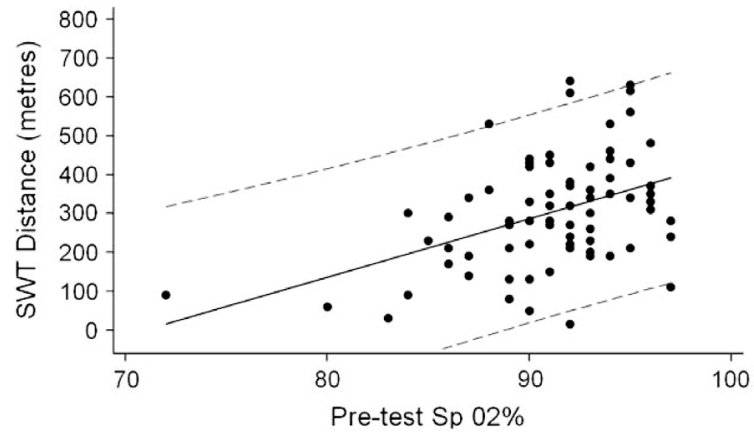

Figure 1. Linear regression association between rest SPO2 and the distance walked in 6MWT.

association between the 6MWT and FEV1. Patients who had walked $<475$ meters had significantly lower FEV1 and SpO2 (peripheral capillary oxygen saturation) dropout occurred in $29 \%$ of patients, especially in patients with FEV1 <60\% (24).

In our study, $53.9 \%$ of patients experienced a SpO2 drop below $90 \%$ during the $6 \mathrm{MWT}$, which was more severe than that of patients in the study by Martin et al (24), indicating a greater reduction in the pulmonary function of our study patients.

In this study, school attendance of the patients was found as an important factor affecting several fields of the QoL. Borawska-Kowalczyk et al found the same results in their study (21). CF children have many absences from school due to frequent visits to the CF center, hospitalizations or parental refuse because of complications like sleepless nights due to cough or abdominal pain or protection against many infections among peers at school. It should not be neglected that CF children can overcome the burden of their disease as long as they attend school. However, in case of clinical exacerbation of their health status, they leave school and have to take part in individual education. Our results outline the importance of professional help to cope with these complications in CF children.

\section{Conclusion}

Since pulmonary function and QoL were associated and the QoL in our CF patients was lower than other advanced centers of the world, the importance of assessing pulmonary function in these patients should not be neglected. The most commonly used submaximal stress test to evaluate the functional capacity and indicating prognosis is the $6 \mathrm{MWT}$ (25). Hence, 6MWT can be used as an adjunct to FEV1 and other criteria for assessing cardiovascular and physical activity in CF patients.

\section{Limitations of the study}

There are some limitations to this study. The main limitation of the study was the lack of follow up although we encouraged regular visit by giving written and verbal advice to their parents and determining the exact date of visit and discussing the treatment methods in each visit. 
Another limitation of our study was that it was crosssectional and thus cannot be used to provide evidence of causation. Also, the sample size was not sufficient to gain adequate power for factor analysis. We did not control for treatment, and it is unclear what external factors may be influencing a child's QoL and symptom treatment, and the subsequent correlation between the two. As a single center retrospective study, our data may not be representative of the entire pediatric CF population.

\section{Acknowledgements}

Authors would like to acknowledge Department of Internal Medicine at Tehran University of Medical Sciences (Iran) for their great help. We also wish to thank all the children and their parents who participated in this investigation.

\section{Authors' contribution}

MM and FM conducted the research. RS conducted the statistical analysis. FM and SN prepared the primary draft. MM revised and prepared the final manuscript. All authors read and approved the final paper.

\section{Conflicts of interest}

The authors declare that they have no conflict of interests regarding the content of this article.

\section{Ethical considerations}

Ethical issues including plagiarism and double publication have been completely observed by the authors.

\section{Funding/Support}

This paper is a result of fellowship thesis of Farzad Masiha for pediatric pulmonology and, it was financially supported by Tehran University of Medical Sciences, Tehran, Iran (Grant \# 9311464002).

\section{References}

1. VanDevanter DR, Wagener JS, Pasta DJ, Elkin E, Jacobs JR, Morgan WJ, et al. Pulmonary outcome prediction (POP) tools for cystic fibrosis patients. Pediatric pulmonol. 2010;45:115666. doi: 10.1002/ppul.21311.

2. Boussetta K, Khalsi F, Bahri Y, Belhadj I, Tinsa F, Messaoud TB, et al. Cystic fibrosis in Tunisian children: a review of 32 children. Afr Health Sci. 2018;18:664-670. doi: 10.4314/ahs.v18i3.24.

3. Sanders DB, Li Z, Laxova A, Rock MJ, Levy H, Collins J, et al. Risk factors for the progression of cystic fibrosis lung disease throughout childhood. Ann Am Thorac Soc. 2014;11:63-72. doi: 10.1513/AnnalsATS.201309-303OC

4. Stoltz DA, Meyerholz DK, Welsh MJ. Origins of cystic fibrosis lung disease. N Engl J Med. 2015;372:351-62. doi: 10.1056/ NEJMra1300109.

5. Kerem E, Viviani L, Zolin A, MacNeill S, Hatziagorou E, Ellemunter $\mathrm{H}$, et al. Factors associated with FEV1 decline in cystic fibrosis: analysis of the data of the ECFS Patient Registry. Eur Respir J. 2014;43:125-33. doi: 10.1183/09031936.00166412.

6. Lima CA, de Andrade AdFD, Campos SL, Brandão DC, Mourato IP, de Britto MCA. Six-minute walk test as a determinant of the functional capacity of children and adolescents with cystic fibrosis: A systematic review. Respir Med. 2018;137:83-88. doi: 10.1016/j.rmed.2018.02.016.

7. Abbott J, Hurley MA, Morton AM, Conway SP. Longitudinal association between lung function and health-related quality of life in cystic fibrosis. Thorax. 2013;68:149-54. doi: 10.1136/ thoraxjnl-2012-202552.

8. Abbott J, Morton AM, Hurley MA, Conway SP. Longitudinal impact of demographic and clinical variables on health-related quality of life in cystic fibrosis. BMJ Open. 2015;5:e007418. doi: 10.1136/bmjopen-2014-007418.
9. Abbott J, Hart A, Havermans T, Matossian A, Goldbeck L, Barreto $\mathrm{C}$, et al. Measuring health-related quality of life in clinical trials in cystic fibrosis J Cyst Fibros. 2011;10:S82-5. doi: 10.1016/ S1569-1993(11)60013-1.

10. Reinfjell T, Diseth TH, Veenstra M, Vikan A. Measuring healthrelated quality of life in young adolescents: Reliability and validity in the Norwegian version of the Pediatric Quality of Life Inventory ${ }^{\mathrm{TM}} 4.0$ (PedsQL) generic core scales. Health Qual Life Outcomes. 2006;4:61. doi: 10.1186/1477-7525-4-61.

11. Mishra A, Greaves R, Smith K, Carlin JB, Wootton A, Stirling R, et al. Diagnosis of cystic fibrosis by sweat testing: age-specific reference intervals. J Pediatr. 2008;153:758-63. doi: 10.1016/j. jpeds.2008.04.067.

12. Vandekerckhove K, Keyzer M, Cornette J, Coomans I, Pyl F, De Baets $F$, et al. Exercise performance and quality of life in children with cystic fibrosis and mildly impaired lung function: relation with antibiotic treatments and hospitalization. Eur J Pediatr. 2017;176:1689-96. doi: 10.1007/s00431-017-3024-7.

13. Kir D, Gupta S, Jolly G, Kalaivani M, Lodha R, Kabra SK. Health Related Quality of Life in Indian Children with Cystic Fibrosis. Indian Pediatr. 2015;52:403-8. doi: 10.1007/s13312-015-06457.

14. Goldstein SL, Graham N, Burwinkle T, Warady B, Farrah R, Varni JW. Health-related quality of life in pediatric patients with ESRD. Pediatric nephrology. 2006;21:846-50.

15. Kalyva E, Malakonaki E, Eiser C, Mamoulakis D. Health-related quality of life (HRQoL) of children with type 1 diabetes mellitus (T1DM): self and parental perceptions. Pediatric diabetes. 2011;12:34-40.

16. Koscik RL, Douglas JA, Zaremba K, Rock MJ, Splaingard ML, Laxova A, et al. Quality of life of children with cystic fibrosis. J Pediatr. 2005;147:S64-8. doi: 10.1016/j.jpeds.2005.09.001.

17. Stahl M, Joachim C, Wielpütz MO, Mall MA. Comparison of lung clearance index determined by washout of N2 and SF6 in infants and preschool children with cystic fibrosis. J Cyst Fibros. 2019;18:399-406. doi: 10.1016/j.jcf.2018.11.001.

18. Driscoll KA, Modi AC, Filigno SS, Brannon EE, Chamberlin LA, Stark LJ, et al. Quality of life in children with CF: psychometrics and relations with stress and mealtime behaviors. Pediatr Pulmonol. 2015;50:560-7. doi: 10.1002/ppul.23149.

19. Cohen MA, Ribeiro MÂ, Ribeiro AF, Ribeiro JD, Morcillo AM Quality of life assessment in patients with cystic fibrosis by means of the Cystic Fibrosis Questionnaire. J Bras Pneumol. 2011;37:184-92. doi: 10.1590/s1806-37132011000200008.

20. van Horck M, Winkens B, Wesseling G, de Winter-de Groot K, de Vreede I, Jöbsis Q, et al. Factors associated with changes in health-related quality of life in children with cystic fibrosis during 1-year follow-up. Eur J Pediatr. 2017;176:1047-1054. doi: 10.1007/s00431-017-2928-6.

21. Borawska-Kowalczyk U, Bodnar R, Meszaros A, Sands D. Comparison of health-related quality of life among children with cystic fibrosis and their parents in two Eastern European countries. J Cyst Fib. 2015;14:798-804. doi: 10.1016/j. jcf.2015.03.008.

22. Stollar F, Adde FV, Cunha MT, Leone C, Rodrigues JC. Shwachman-Kulczycki score still useful to monitor cystic fibrosis severity. Clinics (Sao Paulo). 2011; 66:979-83. doi: 10.1590/ S1807-59322011000600010.

23. Ketchell RI, Roughton M, Agent P, Gyi K, Hodson ME. Predicting survival in end-stage cystic fibrosis. Respir Med. 2009;103:14417. doi: 10.1016/j.rmed.2009.04.025.

24. Martin C, Chapron J, Hubert D, Kanaan R, Honoré I, Paillasseur $\mathrm{J}-\mathrm{L}$, et al. Prognostic value of six minute walk test in cystic fibrosis adults. Respir Med. 2013;107:1881-7. doi: 10.1016/j. rmed.2013.10.001

25. Lesser DJ, Fleming MM, Maher CA, Kim SB, Woo MS, Keens TG. Does the 6-min walk test correlate with the exercise stress test in children? Pediatr Pulmonol. 2010;45:135-40. doi: 10.1002/ ppul.21125. 